\title{
Efficiency Evaluation of a Matrix Converter with a Boost-Up AC Chopper in an Adjustable Drive System
}

\author{
Kazuhiro Koiwa $^{* a)}$ Student Member, Jun-ichi Itoh ${ }^{*}$ Member
}

(Manuscript received Dec. 4, 2012, revised July 24, 2013)

\begin{abstract}
This paper proposes a circuit topology for a matrix converter with a boost-up AC chopper in the input stage in order to improve the voltage transfer ratio, which is defined as the ratio between the input and output voltages. The proposed system is applied in an IPMSM adjustable speed drive system where the application range of flux-weakening control is wide. In order to drive the motor at the rated speed in the high-torque region, there are three possible solutions: (i) applying flux-weakening control, (ii) boosting up the voltage by the AC chopper or (iii) a combination of both the solutions (i) and (ii). In terms of the total loss, the proposed system with the solutions (ii) or (iii) is compared with the conventional matrix converter by using solution (i). Consequently, the chopper loss in the AC chopper and the copper loss of the motor are calculated theoretically to evaluate the total loss. In addition, the proposed system is demonstrated as a 3.7-kW prototype by experiments. In this paper, the input voltage is degraded so that a larger boost-up ratio can be applied to the AC chopper. Further, the proposed system is compared to the conventional matrix converter by expanding the range of flux-weakening control, which depends on the input voltage. As a result, it is confirmed that the converter efficiency of the proposed system reaches $94.8 \%$ at the maximum point. Furthermore, it is revealed that the efficiency of the proposed system is higher when the rated motor voltage is greater than $107 \%$ of the input voltage.
\end{abstract}

Keywords: matrix converter, V-connection AC chopper, flux-weakening control, IPMSM

\section{Introduction}

A matrix converter (MC), which directly converts an $\mathrm{AC}$ power supply voltage into an AC output voltage of variable amplitude and frequency without large energy storage devices such as electrolytic capacitors have been actively studied recently ${ }^{(1)-(3)}$. The following advantages are realized as compared with a back-to-back (BTB) converter, which consists of a PWM rectifier and a PWM inverter: (i) reduced size, low-weight, and long lifetime owing to the absence of a large electrolytic capacitor in the main circuit; (ii) high efficiency because of a lower number of switching devices in the turn-on current path; and (iii) use of MC avoids the increase in temperature of the switching devices in low-outputfrequency operation. Future applications of the MC in the renewable energy field, such as in hybrid electric vehicle systems and wind power generator systems, are expected. In order to render hybrid electric vehicle systems and home appliances more efficient, a high terminal voltage of the motor is required.

However, one of the disadvantages of the MC is that the voltage transfer ratio, which is defined as the ratio between the output voltage and the input voltage, is reduced to $0.866^{(2)}$. Consequently, the amount of output current of the $\mathrm{MC}$ is greater than that of the BTB system for the same output power. When the rated voltage of the motor applied in a

a) Correspondence to: Kazuhiro Koiwa. E-mail: newkoiwa@stn. nagaokaut.ac.jp

* Nagaoka University of Technology

1603-1, Kamitomioka-machi, Nagaoka-city, Niigata 940-2188, Japan conventional MC is similar to that of the BTB system, fluxweakening control is applied at a lower rotating speed when compared with that of the BTB system ${ }^{(3)-(6)}$. However, there is a possibility that the total efficiency of the system is reduced because the output current is increased. In other words, the motor loss in an adjustable speed drive system inherently increases owing to the implementation of flux-weakening control. One of the solutions is to redesign the motor in order to reduce the rated voltage for application in a conventional MC. However, the development cost increases, and the size of the winding is larger owing to the larger amount of motor current. In addition, the restricted voltage transfer ratio also limits the applicability of the MCs. Therefore, boost-up functionality is important in order to extend the application of the MC.

In order to solve this problem, a matrix-reactance frequency converter (MRFC), which consists of an MC and an AC chopper, has been studied ${ }^{(7)(8)}$. References (7) and (8) showed that the amplitude of the output voltage is controlled such that it is higher than the input voltage. However, the MRFC requires many components including a boost-up reactor and capacitor. In addition, the control of the MRFC becomes complicated because regular synchronization is required between the $\mathrm{MC}$ and the chopper.

On the other hand, another MC, which can only boost-up the voltage, is connected in the previous stage of the $\mathrm{MC}^{(1)}$. In other words, this circuit comprises a back-to-back configuration near the filter capacitor. When the MC operates in the boost-up mode, high efficiency is obtained. However, the number of switching devices is twice that of the conventional $\mathrm{MC}$; thus, the cost increases. 
The authors previously proposed a circuit topology that connects a V-connection AC chopper in the input stage of the $\mathrm{MC}$, which enables boost-up functionality in order to overcome the problems incurred in the past works. The proposed system is applied to an adjustable speed drive system where the application range of flux-weakening control is wide. In the proposed system, flux-weakening control is applied at the same rotating speed of the BTB system because the already insufficient output voltage is increased by the $\mathrm{AC}$ chopper. However, the additional loss caused by the AC chopper occurs in the proposed system structure. Further, it is confirmed that the efficiency of the proposed circuit is higher than that of a BTB system on the basis of the loss analysis ${ }^{(9)}$. This is because the number of devices in the AC chopper where the current passes through is $2 / 3$ less than that of the rectifier in a BTB system.

In this work, the validity of the proposed system in the adjustable speed drive system is evaluated in order to clarify the advantage of the proposed system in comparison with the conventional MC. In order to drive the motor at the rated speed and in the high torque region, there are three possible solutions: (i) application of flux-weakening control, (ii) boost-up of the voltage by the AC chopper, or (iii) a combination of both the solutions (i) and (ii). In terms of the total loss, the proposed system with solutions (ii) or (iii) is compared with the conventional MC by using solution (i). A rated voltage of $180 \mathrm{~V}$ is used for the interior permanent magnet (IPM) motor owing to the limitation in the experimental conditions in order to verify the proposed converter. In addition, the boost-up ratio of the AC chopper cannot be set higher than $180 \mathrm{~V}$. Therefore, flux-weakening control is necessary in order to maintain the output voltage at the rated voltage in the proposed system. Furthermore, the input voltage is degraded because the range of flux-weakening control in the proposed system is expanded when compared with the conventional MC. As a result, the effectiveness of the proposed system is determined in terms of the total loss.

The remainder of this paper is organized as follows. First, the chopper loss in the proposed system and the copper loss of the motor in the conventional MC are described theoretically. Further, the differences between the chopper loss and the copper loss are determined through comparison, where flux-weakening control is implemented in the motor control. Finally, the operation of the proposed system is demonstrated with a $3.7-\mathrm{kW}$ IPM motor through simulation and experiment. In addition, the chopper loss and copper loss are evaluated to clarify the validity of the proposed system.

\section{Derivation of the Chopper Loss}

Figure 1 shows the proposed system in which a Vconnection AC chopper is connected in the input stage of the $\mathrm{MC}^{(10)(11)}$. Eight IGBTs are used in the AC chopper. Each of the bi-directional switches comprises two IGBTs. On the other hand, 18 reverse-blocking IGBTs (RB-IGBT) are used in the MC. The relationship between the input voltage $v_{\text {in }}$ and the output voltage $v_{\text {out }}$ is expressed as

$$
v_{\text {out }}=\beta \cdot \lambda_{m c} \cdot v_{\text {in }}
$$

where $\lambda_{m c}$ is the voltage transfer ratio of the $\mathrm{MC}, \beta$ is the boost-up ratio of the chopper and $v_{i n}$ is the input voltage.

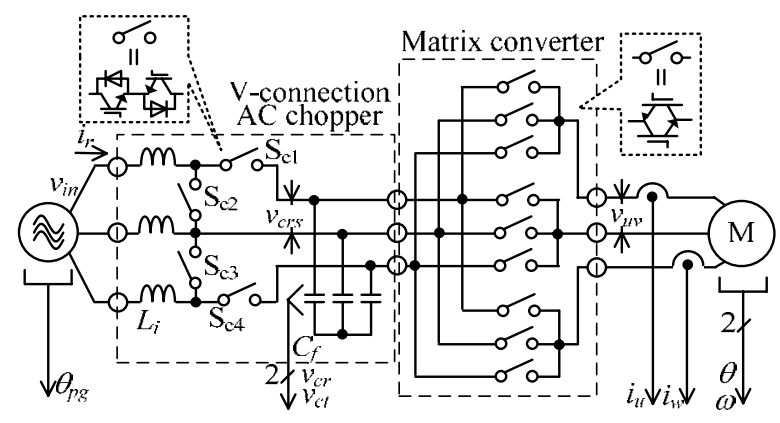

Fig. 1. Circuit configuration of a matrix converter with a boost-up chopper. In order to compensate the output voltage, a V-connection AC chopper is connected on the input side

Basically, the function of the AC chopper is to boost-up the input voltage. Further, feedback control is not required for the filter capacitor because the output of the chopper as in a PWM rectifier is not DC voltage. Therefore, the capacitance and the inductance are not dominated by the voltage control response and the current response from the input side, in contrast to those of a BTB system. For this reason, it is not necessary to use a large inductor or an additional inductor at the primary stage of the AC chopper. As a result, the $\mathrm{V}$-connection AC chopper and these components do not dominate the size and weight in comparison with the original structure of an MC. In addition, the maximum output voltage of the proposed system is determined by the duty ratio of the AC chopper in the boost mode. It should be noted that the switches in the AC chopper do not operate when the output voltage is lower than 0.866 times the input voltage. In other words, the V-connection AC chopper in the proposed system does not generate switching loss in the low output voltage range.

However, conduction loss occurs in the AC chopper even when the switching operation is disabled. Therefore, degradation of the conversion efficiency by adding the AC chopper is an issue of concern.

2.1 Conduction Loss In order to consider the influence of the chopper loss on the proposed system, the chopper losses such as conduction loss and switching loss are theoretically derived in this section.

First, the conduction loss of $\mathrm{S}_{\mathrm{c} 1}$ is expressed as

$$
P_{c o n_{S} S 1}=\frac{1}{\pi} \int_{0}^{\pi} v_{c e} i_{r} d \omega t \ldots \ldots \ldots \ldots \ldots \ldots \ldots \ldots
$$

where $v_{c e}$ is the on-state voltage of $\mathrm{S}_{\mathrm{c} 1}$, which is expressed by (3); and $i_{r}$ is the input current.

$$
v_{c e}=k_{\text {con } 1} i_{r}+k_{\text {con } 2} \cdots
$$

It is noted that $k_{c o n} 1$ and $k_{\text {con } 2}$ are the coefficients defined from the on-state voltage characteristics mentioned in the datasheet of the switching device. In this paper, SK80GM063 manufactured by SEMIKRON is used as the chopper device. The rated voltage and rated current of this IGBT are $600 \mathrm{~V}$ and $81 \mathrm{~A}$, respectively. From these equations, the conduction loss of $\mathrm{S}_{\mathrm{c} 1}$ is introduced as

$$
P_{c o n \_} S_{1}=\frac{k_{c o n 1}}{\beta} I_{i n}^{2}+\frac{2 \sqrt{2}}{\pi} \frac{k_{c o n 2}}{\beta} I_{i n}
$$




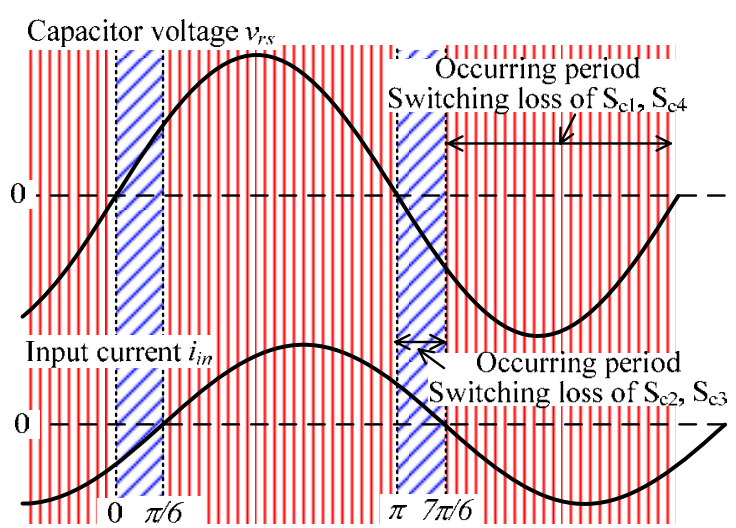

Fig. 2. Integral period of the switching loss of the AC chopper. Switching loss occurs during different periods among each switching device

where, $I_{\text {in }}$ is the effective value of the input current. Similarly, the conduction loss of $\mathrm{S}_{\mathrm{c} 2}$ is expressed by

$$
P_{c o n \_S 2}=\frac{(\beta-1) k_{c o n 1}}{\beta} I_{\text {in }}^{2}+\frac{2 \sqrt{2}}{\pi} \frac{(\beta-1) k_{\text {con } 2}}{\beta} I_{\text {in }} \ldots
$$

It is noted that the equations concerning the conduction losses of $\mathrm{S}_{\mathrm{c} 4}$ and $\mathrm{S}_{\mathrm{c} 3}$ are equivalent to (4) and (5), respectively.

2.2 Switching Loss Figure 2 shows the integral period to calculate the switching loss. The switching loss of the $\mathrm{AC}$ chopper is proportional to the product of the capacitor voltage $v_{c r s}$ and $i_{r}$. Moreover, the integral period is different among the switching devices. In other words, the integral period of $S_{c 1}$ and $S_{c 4}$ is from $5 \pi / 6$ to $\pi$, whereas the integral period of $S_{\mathrm{c} 2}$ and $S_{\mathrm{c} 3}$ is from $\pi / 6$ to $\pi$. Thus, the switching losses $P_{t o n_{-} s 1}$ and $P_{\text {ton_s } 2}$ are expressed as

$$
\begin{aligned}
& P_{\text {ton_S } 1}=\frac{1}{\pi} \int_{\frac{5}{6} \pi}^{\pi} e_{o n} f_{s} \frac{v_{r s}}{V_{s}} d \omega t \\
& =\frac{\sqrt{2} V_{\text {in }} f_{s}}{24 \pi V_{s}}(\beta-1)\left[(\sqrt{6} \pi-6) k_{\text {ton } 1} I_{\text {in }}+12(\sqrt{3}-2) k_{\text {ton } 2}\right] \\
& \quad \ldots \ldots \ldots \ldots \ldots \ldots(6) \\
& P_{\text {ton_S2 }}=\frac{1}{\pi} \int_{\frac{\pi}{6}}^{\pi} e_{o n} f_{s} \frac{v_{r s}}{V_{s}} d \omega t \\
& =\frac{\sqrt{2} \beta V_{\text {in }} f_{s}}{24 \pi V_{s}}\left[(5 \sqrt{6} \pi+3 \sqrt{2}) k_{\text {ton } 1} I_{\text {in }}+12(1+\sqrt{3}) k_{\text {ton } 2}\right]
\end{aligned}
$$

where, $V_{s}$ is the nominal voltage when the switching loss characteristics mentioned in the datasheet are used, and $f_{s}$ is the switching frequency of the AC chopper. $V_{i n}$ is the effective value of the input voltage. In addition, $e_{o n}$ is instantaneous switching loss which is characterized by (8).

$$
e_{\text {on }}=k_{\text {ton } 1} i_{r}+k_{\text {ton } 2}
$$

It is noted that $k_{\text {ton } 1}$ and $k_{\text {ton } 2}$ are the coefficients defined from the switching loss characteristics mentioned in the datasheet of the switching devices. Furthermore, the equations concerning the switching loss of $\mathrm{S}_{\mathrm{c} 4}$ and $\mathrm{S}_{\mathrm{c} 3}$ are equivalent to (6) and (7), respectively.

In order to validate these equations, the calculation results

\begin{tabular}{|c|c|c|c|c|}
\hline \multicolumn{3}{|c|}{ Parameters of switching device(SK80GM063) } & \multirow{2}{*}{\begin{tabular}{c|} 
Configuration system \\
Stray inductence \\
\end{tabular}} & \multirow{3}{*}{\begin{tabular}{|c|}
$\begin{array}{c}A C \\
\text { chopper }\end{array}$ \\
- \\
\end{tabular}} \\
\hline \multirow{2}{*}{$\begin{array}{c}\text { On-state voltage } \\
\text { characteristic }\end{array}$} & $k_{\text {cout }}(\mathrm{V} / \mathrm{A})$ & 0.0182 & & \\
\hline & \begin{tabular}{|l|}
$k_{\text {COHL } 2}(\mathrm{~V})$ \\
\end{tabular} & 0.9773 & Stray capacitance & \\
\hline \multirow{2}{*}{$\begin{array}{l}\text { Switching loss } \\
\text { characteristic }\end{array}$} & $k_{\text {tolit }}(\mathrm{J} / \mathrm{A})$ & 0.00005 & \multirow{2}{*}{ Load } & \multirow{2}{*}{\begin{tabular}{|c|} 
Constant \\
current \\
source \\
\end{tabular}} \\
\hline & $\begin{array}{lll}k_{101 l_{2} 2} & (\mathrm{~J}) \\
\end{array}$ & 0.0 & & \\
\hline \multicolumn{2}{|l|}{$\begin{array}{l}\text { Boost-up ratio of } \\
\text { AC chopper } \beta\end{array}$} & 1.15 & Input reactor $L_{i}$ & $2 \mathrm{mH}$ \\
\hline \multicolumn{2}{|c|}{ Input line voltage $V_{i n}$} & $200 \mathrm{~V}$ & Filter capacitor $C_{f}$ & $14.2 \mu \mathrm{F}$ \\
\hline \multicolumn{2}{|c|}{ Switching frequency $f_{s}$} & $10 \mathrm{kHz}$ & $\begin{array}{l}\text { Damping resistor } R_{d} \\
\left.\text { (connected at } C_{f}\right)\end{array}$ & $1.0 \Omega$ \\
\hline \multicolumn{2}{|l|}{$\begin{array}{l}\text { Nominal voltage } \\
\text { at switching test } V_{s}\end{array}$} & $300 \mathrm{~V}$ & & \\
\hline
\end{tabular}
are compared with the loss simulation results, which are obtained by PSIM. Table 1 lists the calculation parameters. In
Table 1. Parameters used to calculate the chopper loss. The parameters of the switching device are obtained from the datasheet

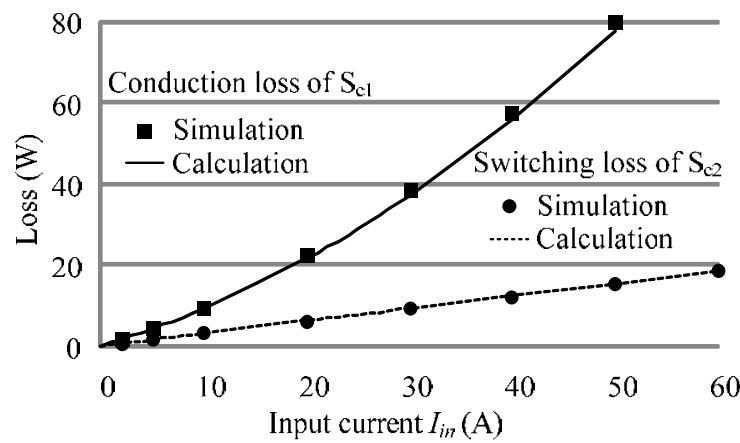

Fig. 3. Chopper loss, which includes the conduction loss and switching loss, for the input current shown in the calculation and simulation results. In order to evaluate the derived equation of the chopper loss, the calculation results are compared with the simulation results

the loss simulation, the circuit configuration includes only the AC chopper, and the current source is used as the load. In addition, the stray inductance and stray capacitance are not taken into consideration.

Figure 3 shows the conduction and switching losses of the AC chopper obtained by theoretical calculation and simulation ${ }^{(12)}$. It is noted that the chopper loss shown in the calculation results is the sum of (4), (5), (6), and (7). As a result, the calculation results agree well with the simulation results. Thus, the validity of the derived equations of the chopper loss is confirmed. In other words, the chopper loss is easily calculated from the input current.

\section{Derivation of the Copper Loss of the IPM Motor}

As an IPM motor is driven in the high rotating speed region, it is necessary to apply flux-weakening control in motor control ${ }^{(3)-(6)}$. However, the copper loss of the IPM motor is increased because the $\mathrm{d}$-axis current flows according to fluxweakening control. In this section, the control strategy of the proposed system, that is, flux-weakening control is explained. Additionally, the equation of the copper loss, which is increased by the flux-weakening control, is expressed corresponding to the $\mathrm{d}$-axis and $\mathrm{q}$-axis currents.

\subsection{Control Strategy of the Proposed System}

Figure 4 shows the control block diagram of the proposed system. First, the duty command of the chopper $d_{c}^{*}$ for the $\mathrm{V}$-connection AC chopper is expressed by

$$
d_{c}^{*}=\frac{\lambda_{m c}}{v_{c}^{*}} .
$$




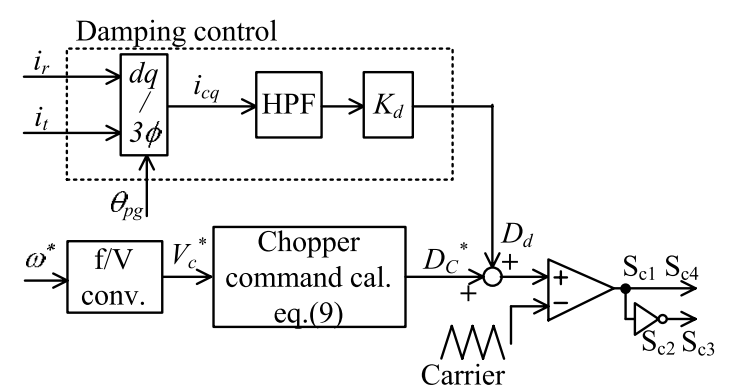

(a) AC chopper

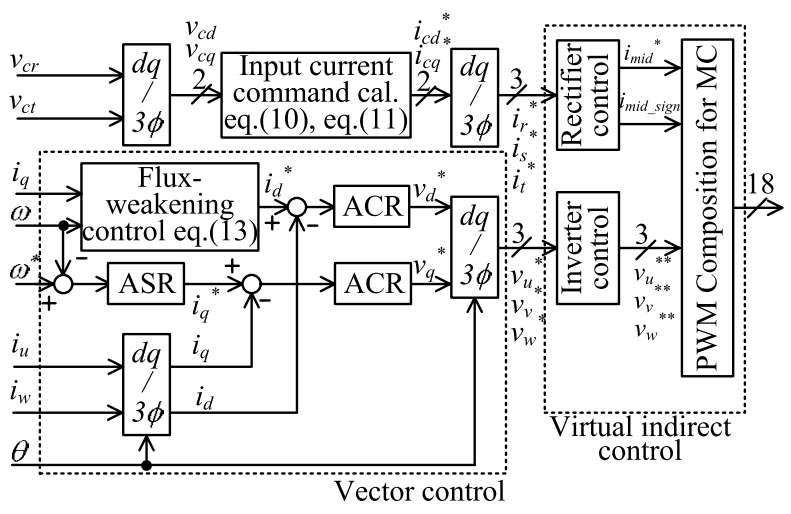

(b) Matrix converter

Fig. 4. Control block diagrams of the (a) AC chopper and (b) MC. Damping control is applied to the AC chopper control to suppress the input filter resonance. The motor is driven by vector control. In MC control, virtual indirect control is applied. The MC with a boost-up chopper is easily controlled because both chopper control and MC control are independent

where $v_{c}^{*}$ is the voltage command, which is converted from the rotating speed command. In this work, $\lambda_{m c}$ is considered as the limitation of the voltage transfer ratio of the $\mathrm{MC}$, which is 0.866 . Although, the voltage transfer ratio in the proposed system is improved by the AC chopper, resonance distortion due to the input filter occurs. Therefore, damping control is applied in the AC chopper control ${ }^{(9)}$.

On the other hand, the pulse pattern of the MC is generated by the virtual indirect control method ${ }^{(13)}$. The virtual indirect control method is divided into input current control and output voltage control. Thus, the conventional control method is applied for each control. The input current commands $i_{c d}^{*}$ and $i_{c q}^{*}$ are generated from the capacitor voltage in order to maintain a constant output power ${ }^{(14)}$. Thus, these parameters are expressed as

$$
\begin{aligned}
i_{c d}^{*} & =\frac{p^{*} \cdot v_{c d}-q^{*} \cdot v_{c q}}{v_{c d}^{2}+v_{c q}^{2}} . \\
i_{c q}^{*} & =\frac{p^{*} \cdot v_{c q}-q^{*} \cdot v_{c d}}{v_{c d}^{2}+v_{c q}^{2}}
\end{aligned}
$$

where, $p^{*}$ is the active instantaneous power command and $q^{*}$ is the reactive instantaneous power command. It is noted that $p^{*}$ is equal to 1 p.u., and $q^{*}$ is equal to 0 p.u. in this work, in order to obtain unity power factor. In addition, $v_{c d}$ and $v_{c q}$ are the d-axis and q-axis capacitor voltages, respectively.

In order to drive the IPM motor in a high rotating speed area within the output voltage limitation of the $\mathrm{MC}$, it is necessary to apply flux-weakening control in MC control. This is

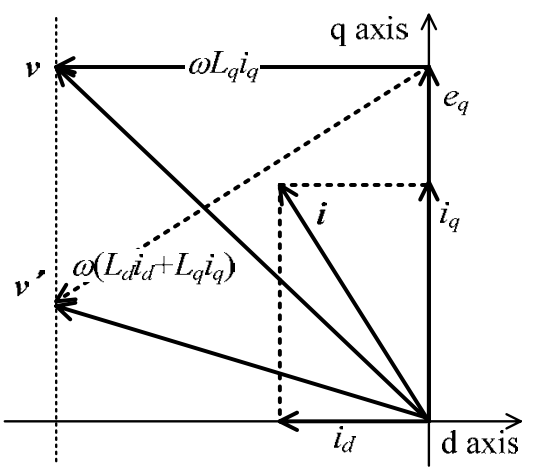

Fig. 5. Vector diagram of flux-weakening control. In order to suppress the output voltage, the negative d-axis current flows. The motor is driven at a high rotating speed by flux-weakening control

because the back electromotive force increases with increasing rotating speed. The output voltage, which is necessary to control the motor, is degraded by flux-weakening control. Therefore, the d-axis current $i_{d}$ for the flux-weakening control is introduced.

Figure 5 shows the vector diagram of flux-weakening control, where $e_{q}$ is the back electromotive force, and $v$ and $v^{\prime}$ are the terminal voltages in the IPM motor without and with fluxweakening control, respectively. It is noted that the winding resistance of the IPM motor $R_{w}$ is not considered. The fluxweakening control in the IPM motor equally weakens the magnetic flux in the permanent magnet from the d-axis armature magnetic flux. As a result, the rotating speed area is extended by implementing flux-weakening control. As shown in Fig. 5, $V_{\text {om }}$, which is the maximum output phase voltage of the MC, is expressed by (12).

$$
\begin{aligned}
& V_{o m}=\sqrt{v_{d}^{2}+v_{q}^{2}} \\
& =\sqrt{\left(\omega L_{q} i_{q}\right)^{2}+\left(\omega L_{d} i_{d}+e_{q}\right)^{2}}
\end{aligned}
$$

Therefore, the d-axis current in the flux-weakening control at the maximum voltage is calculated by (13).

$$
i_{d}=\frac{-e_{q}+\sqrt{V_{o m}^{2}-\left(\omega L_{q} i_{q}\right)^{2}}}{\omega L_{d}}
$$

3.2 Copper Loss Caused by Flux-weakening Control

The motor is driven in the high rotating speed region by flux-weakening control. However, the motor current is increased owing to flux-weakening control. As a result, the motor loss and the converter loss increase. In order to validate the AC chopper, it is evinced that the copper loss is decreased by the proposed system. In particular, the equation for the copper loss subject to the input line voltage is calculated.

First, the torque of the IPM motor is expressed by

$$
T=P_{n}\left[\frac{e_{q}}{\omega} i_{q}+\left(L_{d}-L_{q}\right) i_{d} i_{q}\right]
$$

where, $P_{n}$ is the number of pole pairs. As shown in (14), the torque of the IPM motor depends on the d-axis and q-axis currents.

As shown in (13) and (14), the d-axis and q-axis currents depend on $V_{o m}$. Additionally, $V_{o m}$ is determined by the input line voltage and voltage transfer ratio. In other words, 
in order to calculate the copper loss of the motor as $V_{\text {in }}$ is changed, the q-axis current is introduced for $V_{o m}$. Thus, $V_{o m}$ is expressed by (15) using (13) and (14).

$$
V_{o m}=\sqrt{\left[\frac{L_{d}}{\left(L_{d}-L_{q}\right)}\left(\frac{\omega T}{P_{n}}-\frac{L_{q}}{L_{d}} e_{q} i_{q}\right) \frac{1}{i_{q}}\right]^{2}+\left(\omega L_{q} i_{q}\right)^{2}}
$$

It is noted that the q-axis current should be obtained to derive the copper loss. However, (15) cannot obtain the q-axis current. For this reason, the q-axis current is calculated by numerical analysis. It should be noted that the q-axis current is limited by (16).

$$
\left|i_{q}\right| \leq \frac{V_{o m}}{\omega L_{q}}
$$

On the other hand, the d-axis current is calculated by (13). Therefore, the copper loss $P_{c}$ is expressed by

$$
P_{c}=3 R_{w} I_{o}^{2}=3 \cdot R_{w} \cdot \frac{\left(i_{d}^{2}+i_{q}^{2}\right)}{2}
$$

where, $R_{w}$ is the primary winding resistance of the IPM motor. In addition, $I_{o}$ is the R.M.S. of the output current.

3.3 Comparison of the Chopper Loss with the Copper Loss Figure 6 shows the calculation results of the comparison between the additional chopper loss and the additional copper loss due to flux-weakening control. It is noted that the copper loss is calculated by the motor parameters, which are listed in Table 2. The input line voltage $V_{\text {in }}$ is changed. Furthermore, the additional copper loss in Fig. 6 is obtained by subtracting the copper loss, which occurs in the conventional MC $P_{C_{-} C M C}$, from that of the proposed system $P_{C \_B M C}$. The copper loss of the proposed system does not depend on the input voltage because the constant output voltage of $180 \mathrm{~V}$ is controlled by the AC chopper. In addition, application range of flux-weakening control in the IPM motor is not wide. Therefore, in order to extend the application, the input voltages of the proposed system and the conventional MC are degraded. Further, it is possible to simulate the high rotating speed of the IPM motor. As a result, the range of the additional copper loss $\left(P_{C_{-} C M C}-P_{C_{-} B M C}\right)$ is negative. This is because the phase of the motor current increases when controlling the d-axis current. As a result, the power factor of the motor is improved, and the output current decreases. Therefore, the copper loss in the conventional MC is lower than that of the proposed system. Additionally, the chopper loss is greater than the copper loss when the ratio between the rated motor voltage $V_{n}$ and $V_{\text {in }}\left(V_{n} / V_{\text {in }}\right)$ is less than 1.01 p.u. On the other hand, as $V_{n} / V_{\text {in }}$ is greater than 1.01 p.u., the chopper loss is lower than the copper loss. This is because the motor current and the copper loss increase owing to flux-weakening control when $V_{n} / V_{\text {in }}$ is higher.

Therefore, as the motor parameters and the switching device characteristics are known, the effective region of the AC chopper is calculated by (4), (5), (6), (7), (13), and (15). In other words, it is not necessary to analyze the total loss by experiment. In terms of efficiency, the effectiveness of the proposed system is determined by only referring to the motor and device parameters without an experiment.

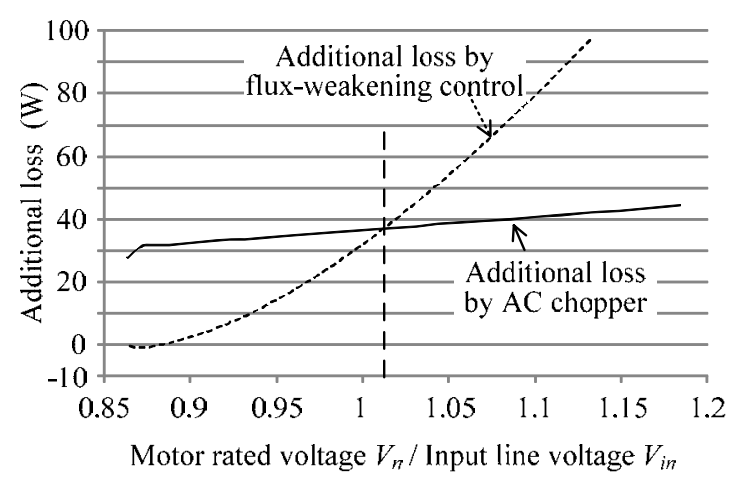

Fig. 6. Loss comparison between the additional loss by flux-weakening control and the AC chopper when the input line voltage is changed. The rated motor voltage is $180 \mathrm{~V}$ and constant. When the motor and device parameters of the chopper are well-known, the effectiveness of the boost-up chopper can be calculated

Table 2. IPM motor parameters. The copper loss is calculated from these parameters

\begin{tabular}{|c|c|c|c|c|}
\hline \multicolumn{2}{|c|}{ Rotating speed $\omega$} & $1800 \mathrm{rpm}$ & Output control & Vector control \\
\hline \multicolumn{2}{|c|}{ Input frequency } & $50 \mathrm{~Hz}$ & Commutation & $\begin{array}{l}\text { Voltage and } \\
\text { Current-type }\end{array}$ \\
\hline \multirow{2}{*}{$\begin{array}{c}\text { Carrier } \\
\text { frequency }\end{array}$} & Chopper & \multirow{2}{*}{$10 \mathrm{kHz}$} & \multirow{2}{*}{$\mathrm{MC}$ control } & \multirow{2}{*}{$\begin{array}{l}\text { Virtual indirect } \\
\text { control }\end{array}$} \\
\hline & $\mathrm{MC}$ & & & \\
\hline \multirow{2}{*}{$\begin{array}{c}\text { Response } \\
\text { angular } \\
\text { frequency } \omega_{r}\end{array}$} & ACR & $3000 \mathrm{rad} / \mathrm{s}$ & \multirow{2}{*}{ Load } & \multirow{2}{*}{$\begin{array}{l}\text { 3.7-kW } \\
\text { IPM motor }\end{array}$} \\
\hline & ASR & $200 \mathrm{rad} / \mathrm{s}$ & & \\
\hline \multicolumn{2}{|c|}{ Input reactor $L_{i}$} & $2 \mathrm{mH}$ & Switch of MC & $18 \mathrm{MBI} 100 \mathrm{~W}-120 \mathrm{~A}$ \\
\hline \multicolumn{2}{|c|}{ Filter capacitor $C_{f}$} & $14.2 \mu \mathrm{F}$ & Switch of chopper & SK80GM063 \\
\hline \multicolumn{2}{|c|}{$\begin{array}{l}\text { Damping resistor } R_{d} \\
\text { (Conventional } \mathrm{MC} \text { ) }\end{array}$} & $32.7 \Omega$ & & \\
\hline
\end{tabular}

\begin{tabular}{|c|c|c|c|}
\hline $\begin{array}{c}\text { Rated mechanical } \\
\text { power } P_{n t}\end{array}$ & $3.7 \mathrm{~kW}$ & Winding resistance $R_{\mathrm{u}}$ & $0.693 \Omega$ \\
\hline $\begin{array}{c}\text { Back electro-motive } \\
\text { force } e_{q}\end{array}$ & $151 \mathrm{~V}$ & $\begin{array}{c}\text { d-axis } \\
\text { inductance } L_{d}\end{array}$ & $6.2 \mathrm{mH}$ \\
\hline Rated voltage $V_{t \prime}$ & $180 \mathrm{~V}$ & $\begin{array}{c}\text { q-axis } \\
\text { inductance } L_{q}\end{array}$ & $15.3 \mathrm{mH}$ \\
\hline Rated current $I_{n}$ & $14 \mathrm{~A}$ & Inertia moment $J$ & $0.0212 \mathrm{kgm}^{2}$ \\
\hline $\begin{array}{c}\text { Synchronous speed } \\
\omega_{s}\end{array}$ & $1800 \mathrm{rpm}$ & $\begin{array}{c}\text { Number of pole pairs } \\
P_{n}\end{array}$ & 3 \\
\hline Rated torque $T_{c R}$ & $19.6 \mathrm{Nm}$ & & \\
\hline
\end{tabular}

Table 3. Simulation and experimental conditions

\section{Simulation and Experimental Results}

4.1 Fundamental Operation of the Proposed System by the IPM Motor Load In this section, the accelerated operation and the steady operation of the IPM motor are implemented through simulation and experiment. Table 3 summarizes the conditions for the simulation circuit and the experiment. It is noted that the output line voltage is observed by a low-pass filter (LPF) with a $1.5-\mathrm{kHz}$ cut-off frequency in order to observe the low-frequency component distortion.

Figure 7 shows the operation waveforms of the proposed system and the conventional MC. It is noted that the input line voltage is $200 \mathrm{~V}$. In addition, the rated voltage of the motor is set to $240 \mathrm{~V}$. The rotating speed and the d-axis and q-axis currents are normalized at the synchronous speed and rated current, respectively. Accordingly, the motor is driven without flux-weakening control by the proposed system because the voltage is increased to $240 \mathrm{~V}$. On the other hand, in order to drive the motor at a high speed and in the high-torque 

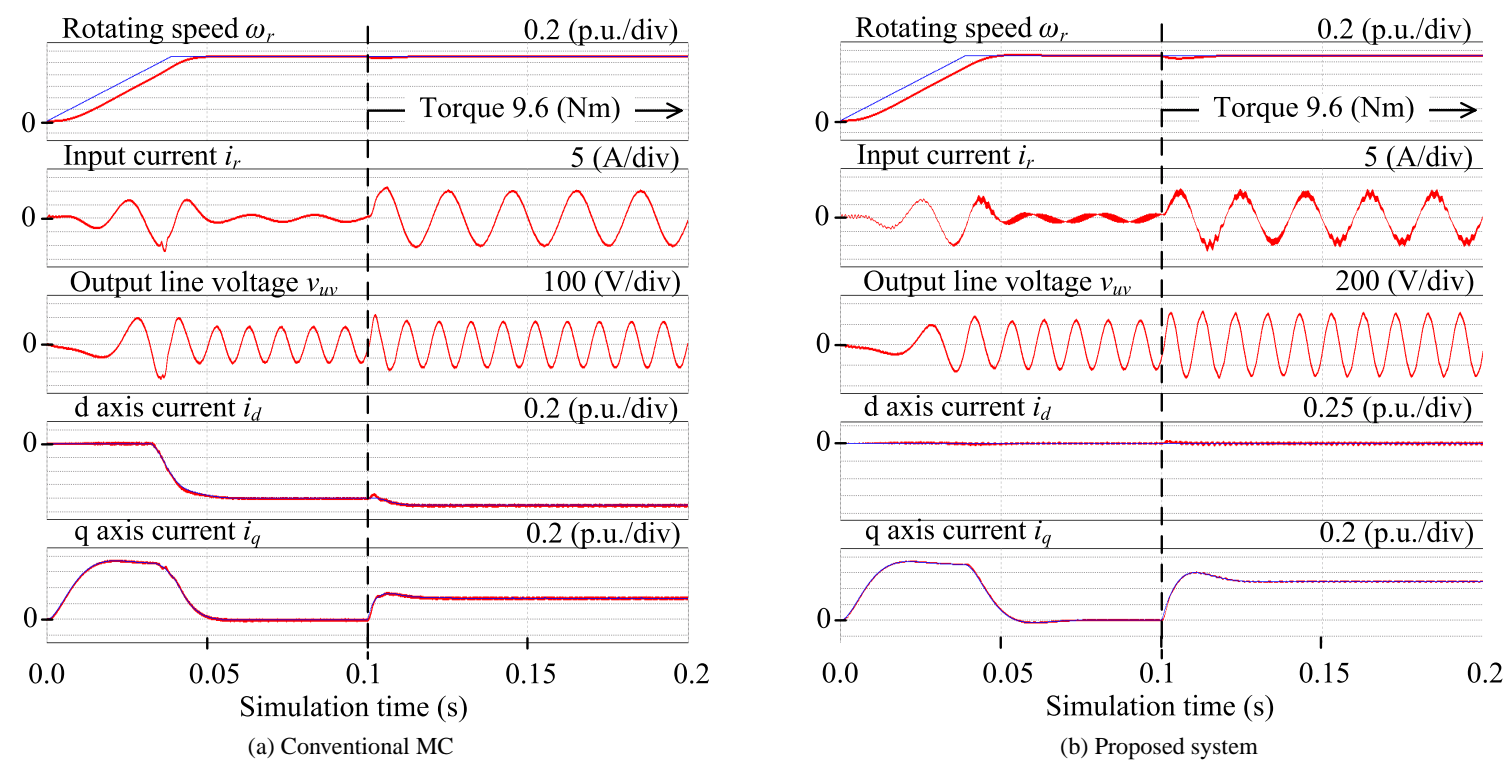

Fig. 7. Acceleration test and transient response of the load torque for (a) the conventional MC and (b) the proposed system shown in the simulation results. The rotating speed of the motor is $2000 \mathrm{r} / \mathrm{min}$. It is assumed that the rated voltage of the motor is $240 \mathrm{~V}$. The output voltages of the conventional MC and proposed system are limited to $173 \mathrm{~V}$ and $240 \mathrm{~V}$, respectively

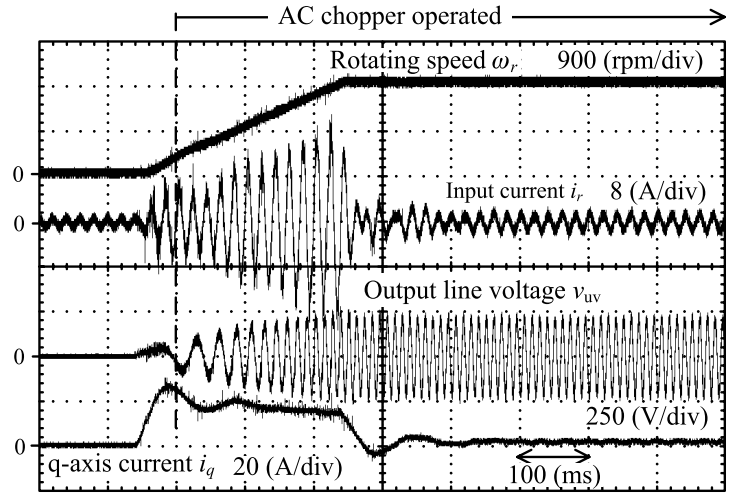

Fig. 8. Experimental acceleration test by the MC with a boost-up chopper. The acceleration time is $0.3 \mathrm{~s}$. The boost-up AC chopper operates when the rotating speed is greater than $360 \mathrm{r} / \mathrm{min}$

region with the conventional $\mathrm{MC}$, flux-weakening control is necessary because the output voltage of the conventional MC is limited to $173 \mathrm{~V}$.

Figure 8 shows the experimental acceleration tests conducted on the IPM motor, which is driven by the proposed system with vector control. It is noted that a four-step commutation sequence, which uses the voltage of the filter capacitors, is applied to the experiment ${ }^{(15)}$. As shown in Fig. 8, the $\mathrm{AC}$ chopper operates while the rotating speed $\omega^{*}$ is greater than $360 \mathrm{r} / \mathrm{min}$ in order to suppress the input filter resonance by damping control. Additionally, it is confirmed that the input and q-axis currents are not drastically changed as the AC chopper begins operating. Therefore, the proposed system continuously improves the voltage transfer ratio of the MC.

Figure 9 shows the steady operation of the IPM motor, which is driven at a rated torque by the proposed system. It is noted that damping control is applied in the AC chopper. Moreover, in order to reduce commutation errors, a hybrid commutation which combines voltage and current commutations, is adopted. In addition, the boost-up ratio of the AC chopper and the input line voltage are set to 1.15 and $180 \mathrm{~V}$, respectively. Furthermore, in order to confirm the fundamental operation of the proposed system, the motor speed is controlled at a rated rotating speed by the load-side motor. In other words, an automatic speed regulator (ASR) is not used.

Figure 9-(a) shows the static operation waveforms of the proposed system. According to the waveforms, it is confirmed that the d-axis and q-axis currents are maintained at a constant value by the automatic current regulator (ACR). On the other hand, the total harmonic distortion (THD) of the input current is $6.6 \%$.

Figure 9-(b) shows the spectrum of the input current obtained by a fast Fourier transform (FFT). It is noted that the input current value is normalized to the fundamental current, which is equal to $12.9 \mathrm{~A}$. In addition, $f_{i}$ and $f_{o}$ are the input and output frequency, respectively. According to the FFT results, large harmonic distortion does not occur. However, the spectrum of the input current occurs at $6 f_{i}-f_{i}$ and $6 f_{i}+f_{i}$ owing to the dead-time error.

Figure 10 shows the output line voltage characteristic based on the output power of the motor. In this work, fluxweakening control is applied at a voltage within the rated voltage of the motor when the load torque is changed at the rated speed. It is noted that the input line voltage is set to $180 \mathrm{~V}$. The rated voltage of the IPM motor $V_{n}$ is $180 \mathrm{~V}$. Thus, it is necessary to limit the output line voltage to $180 \mathrm{~V}$ by flux-weakening control. According to these results, it is confirmed that the output line voltage is limited to $180 \mathrm{~V}$ by applying flux-weakening control. Thus, flux-weakening control is validated by the experimental results. When the load torque is changed at the rated speed of the motor, fluxweakening control is applied at an output power of the motor of $1.3 \mathrm{~kW}$ in the proposed system. On the other hand, fluxweakening control is applied at an output power of the motor of $400 \mathrm{~W}$ in the conventional MC. In other words, as soon the output power of the motor exceeds a $400-\mathrm{W}$ load, the daxis current increases owing to flux-weakening control in the 


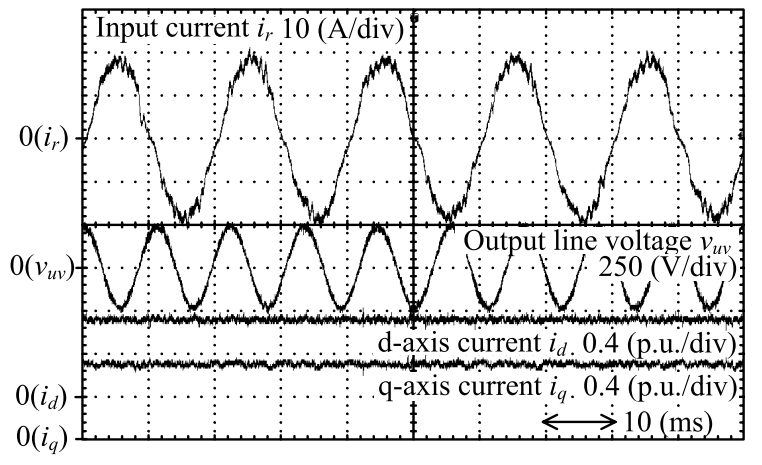

(a) Operation waveforms of proposed circuit

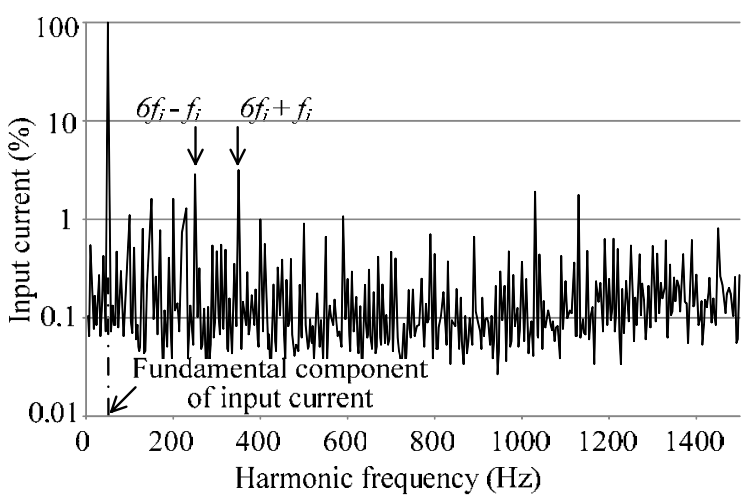

(b) Spectrum of input current by FFT

Fig. 9. Steady operation at the rated torque by experiment. The hybrid commutation is applied in the AC chopper and the MC. These figures show (a) the operation waveforms and (b) the spectrum of the input current by FFT. The spectrum of the input current is normalized at $12.9 \mathrm{~A}$. The polarity of the d-axis current is reversed. The input current THD is $6.6 \%$. The effective value of the output line voltage is $180 \mathrm{~V}$ owing to flux-weakening control. One of main causes of input current distortion is the dead time error

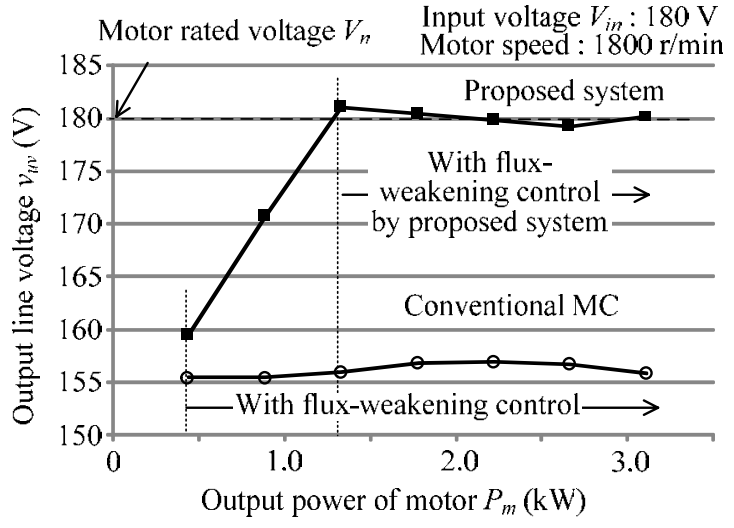

Fig. 10. Output line voltage characteristic obtained with flux-weakening control in the proposed system and conventional MC. The rated motor voltage and input line voltage are $180 \mathrm{~V}$. As a result, the output line voltage is limited to $180 \mathrm{~V}$ by flux-weakening control

conventional MC. As a result, the copper loss of the IPM motor is increased owing to flux-weakening control.

Figure 11 shows the converter efficiency characteristic and the input power factor characteristic, proportional to the output power of the MC. First, it is confirmed that the unity power factor is obtained at an output power greater than $1 \mathrm{~kW}$. On the other hand, the converter efficiency at the maximum point is $94.8 \%$ at an output power of $2.3 \mathrm{~kW}$.

Figure 12 shows the input current THD characteristic for the output power of the converter. It is noted that the currenttype damping control is applied to the AC chopper in all regions. Moreover, the hybrid commutation, which is a combination of the voltage commutation and the current commutation $^{(15)}$, is applied in the AC chopper and MC. Furthermore, optimal design the gain is required for damping control.

From these results, the validity of the proposed system in the adjustable drive system is confirmed.

4.2 Loss Analysis of the Conventional MC and the Proposed System In order to validate the proposed system in terms of efficiency, the total loss characteristic of the proposed system is compared with that of the conventional MC through simulations and experiments.

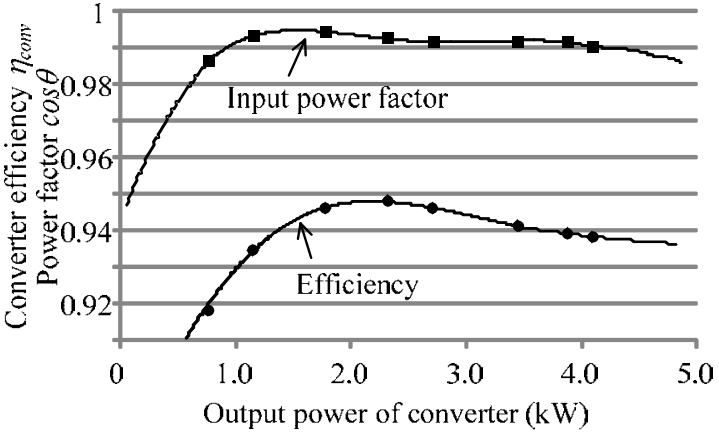

Fig. 11. Converter efficiency and input power factor characteristics of the proposed system. The converter efficiency at the maximum point is $94.8 \%$ at an output power of $2.3 \mathrm{~kW}$. The input power factor at the maximum point is 0.994 at an output power of $1.8 \mathrm{~kW}$

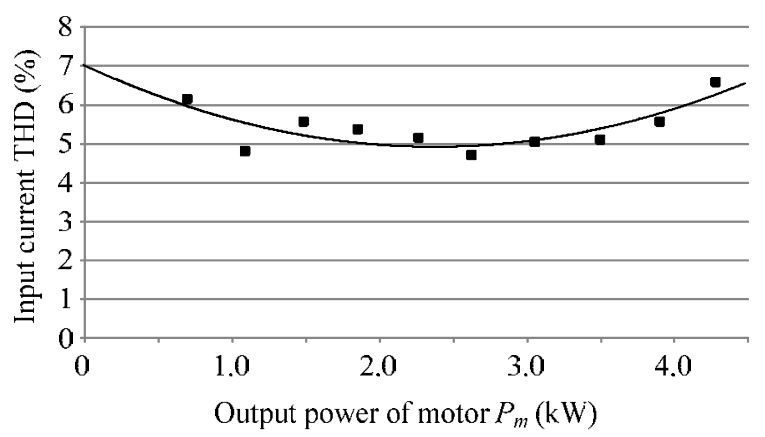

Fig. 12. Input current THD characteristic in the proposed system. The damping gain $K_{d}$ is 0.5 (p.u.). The input current THD is below 7\% in all regions. The minimum THD of the input current is $4.8 \%$ at an output power of $2.6 \mathrm{~kW}$

Figure 13 shows the d-axis current and q-axis current characteristics for $V_{n} / V_{i n}$. It is noted that the experimental results are obtained by the conventional MC. In order to validate the equation of the copper loss, the calculation results are compared with the experimental results. As shown in Fig. 13(a), the calculation results almost agree with the experimental results. On the other hand, as shown in Fig. 13-(b), the error between the calculation results and the experimental results is approximately $10 \%$. This error is because the winding 


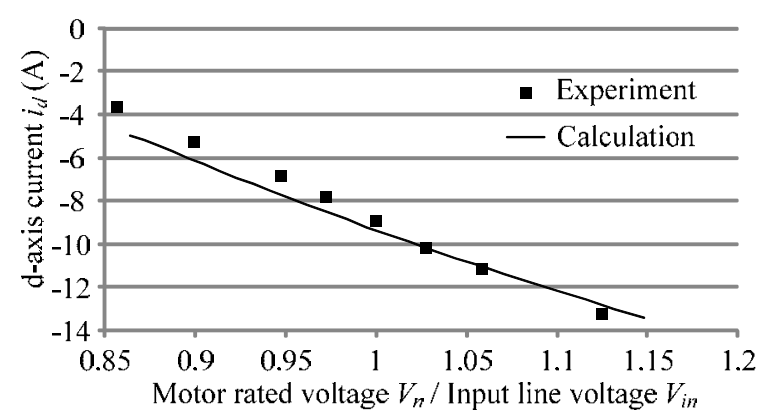

(a) d-axis current

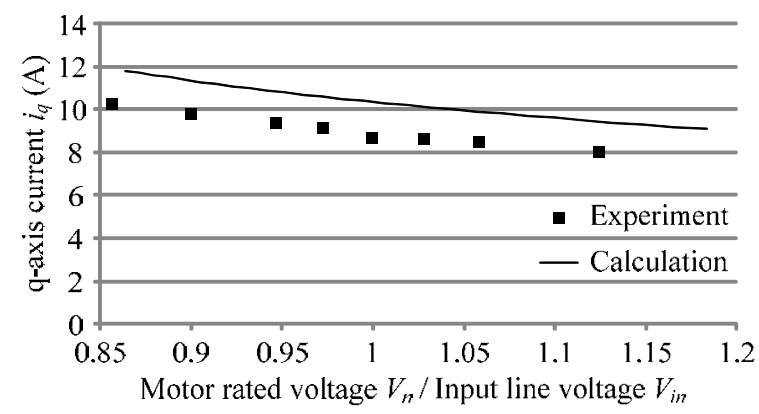

(b) q-axis current

Fig. 13. d-axis current and q-axis current comparison between the calculation and the experimental results in the conventional MC. The error between the calculation and experimental results is within $10 \%$. The calculation results of the d-axis current and q-axis current agree with the experimental results

resistance of the IPM motor is not considered in (13). However, the trend in the calculation result almost agrees with the experimental result. Thus, the validity of the equations for the copper loss is confirmed. Additionally, as $V_{n} / V_{\text {in }}$ increases, the d-axis current increases. This implies that the compensation value of flux-weakening control increases with $V_{n} / V_{i n}$. On the other hand, the q-axis current decreases as $V_{n} / V_{i n}$ increases. According to (14), the q-axis current decreases when the d-axis current increases when the torque is constant.

Figure 14 shows the loss property determined through simulation. It is noted that the rotating speed is $2000 \mathrm{r} / \mathrm{min}$, the output power of the motor is $2 \mathrm{~kW}$, and the input line voltage is set to $200 \mathrm{~V}$. In practice, the output voltage of the converter cannot be higher because it is assumed that the rated motor voltage is greater than that of the actual motor in the simulation. Therefore, the rated motor voltage is set to $240 \mathrm{~V}$ in the simulation. According to the results, the converter loss of the proposed system is increased owing to the AC chopper. However, taking the IPM motor loss into consideration, the total loss in the proposed system is less than that in the conventional MC. This is because the copper loss of the IPM motor, the conduction loss of the free wheeling diodes (FWDs) and the conduction loss of the IGBTs are increased owing to fluxweakening control in the conventional MC. Therefore, when the rated voltage of the motor is increased, the effective area of the proposed system can be expanded.

Figure 15 shows the total loss comparison between the proposed system and the conventional MC. It is noted that $V_{\text {in }}$ is changed. The total losses, as shown in Fig. 15, between the proposed system and the conventional MC are compared with regard to the effective areas of both systems. Additionally,

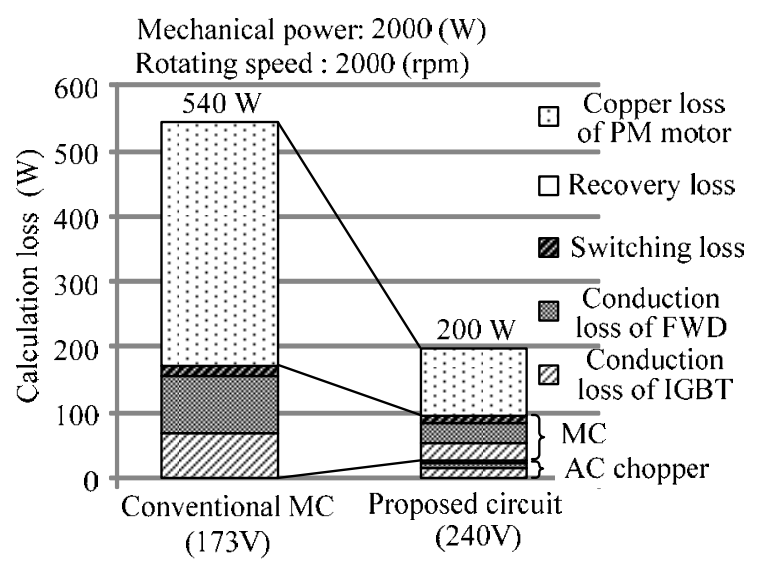

Fig. 14. Loss property in the simulation results showing the total loss comparison between the conventional MC (left side) and the proposed system (right side) with/without flux-weakening control. The rated voltage of the motor is $240 \mathrm{~V}$. In comparison with the conventional MC, the total loss of the proposed system decreases by $60 \%$ because flux-weakening control is not applied

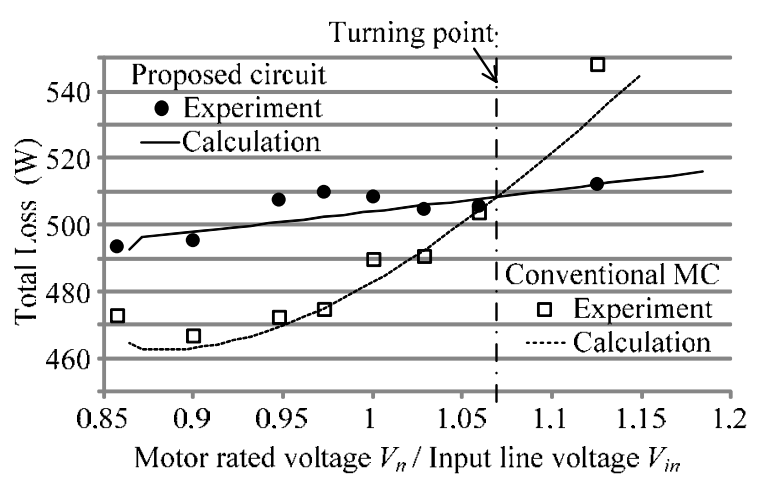

Fig. 15. Total loss comparison between the conventional MC and the proposed system. The calculation results agree with the experimental results. In the case that $V_{n} / V_{\text {in }}$ is greater than $107 \%$, the total loss in the proposed system is less than that in the conventional MC. The validity of the proposed system is determined when the input line voltage is below $93.5 \%$ of the rated motor voltage

the iron loss and the mechanical loss $P_{\text {other }}$ are expressed by (18) in the experiment.

$$
P_{\text {other }}=-125 \cdot\left(V_{n} / V_{\text {in }}\right)+308 \cdots \cdots \cdots \cdots \cdots \cdots \cdots \cdots(18)
$$

Accordingly, the total efficiency of the conventional MC, which applies flux-weakening control, becomes low as the input line voltage decreases. This is because the conduction loss of the converter and the copper loss of the IPM motor increase owing to flux-weakening control.

On the other hand, the AC chopper in the proposed system easily improves the already decreased input line voltage. For this reason, high efficiency of the proposed system is achieved in the adjustable drive system.

According to the experimental results, when the ratio of the input line voltage and the rated motor voltage is greater than 1.07 p.u., the total loss of the proposed system is less than that of the conventional MC. However, in comparison with Fig. 6, the turning points in both the results are different. Further, the error between the calculation results and the experimental results is $5.6 \%$. This is because the iron loss and 


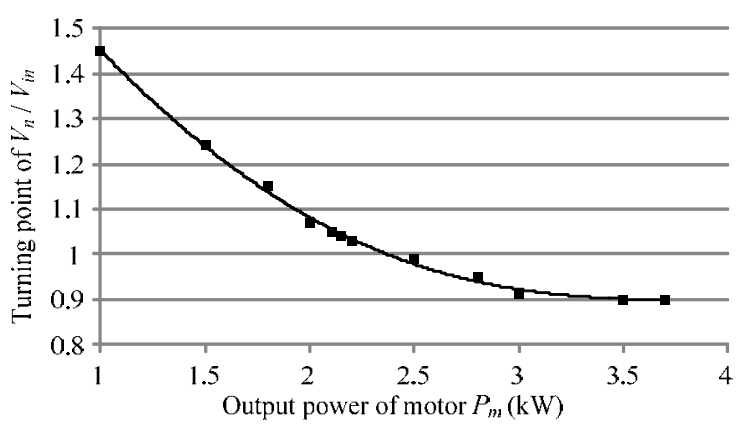

Fig. 16. Relationship between the turning point of $V_{n} / V_{i n}$ and the output power of the motor $P_{m}$ by calculation result. The turning point of $V_{n} / V_{i n}$ is the point that the total loss of the proposed system is lower than that of the conventional MC

mechanical loss is not taken into consideration, as shown in Fig. 6. The iron loss depends on the output line voltage and frequency. Therefore, the validity of the proposed system is determined as the rated motor voltage exceeds $107 \%$ of the input voltage.

Figure 16 shows the relationship between the turning point of $V_{n} / V_{i n}$ and the output power of the motor. From this result, it is observed that the turning point of $V_{n} / V_{i n}$, which denotes the effectiveness of the proposed system, is reduced when the output power of the motor is increased. This is because the total efficiency of the conventional MC is drastically degraded in comparison with the proposed system when the output power of the motor is increased. Thus, when the output power of the motor is increased, the effectiveness of the proposed system is expanded. In particular, it is noted that the efficiency of the proposed system is higher than that of the conventional MC at the rated output power of the motor when the rated motor voltage is greater than $90 \%$ of the input voltage.

Finally, when a high rated voltage of the IPM motor is applied, the effective region of the proposed system is theoretically calculated from the abovementioned equations.

\section{Conclusion}

In this work, the validity of the proposed system was evaluated in terms of the efficiency of the IPM motor drive system. Consequently, the chopper loss and copper loss were derived theoretically. Further, the calculation results of the chopper loss agree with the simulation results. On the other hand, the error in the copper loss between the calculation results and the simulation results is less than $10 \%$. As a result, it was confirmed that the chopper loss is less than the copper loss with regard to the effective area.

The proposed system was demonstrated with a $3.7-\mathrm{kW}$ IPM motor. As a result, it was confirmed that the converter efficiency of the proposed system is $94.8 \%$ at a mechanical output power of $2.3 \mathrm{~kW}$. Moreover, the validity of the proposed system was confirmed as the input voltage is below $93.5 \%$ of the rated motor voltage.

In our future work, the damping gain will be optimized. Moreover, the harmonic distortion in the input current will be suppressed.

\section{References}

( 1 ) P.W. Wheeler, J. Rodriguez, J.C. Clare, and L. Empringham: "Matrix Converters: A Technology Review", IEEE Trans. Industry Electronics, Vol.49, No.2, pp.274-288 (2002)

( 2 ) Q. Lei, F.Z.Peng, and B. Ge: "Pulse-Width-Amplitude-Modulated VoltageFed Quasi-Z-Source Direct Matrix Converter with maximum constant boost", pp.641-646 (2012)

( 3 ) D. Casadei, M. Mengoni, G. Serra, A. Tani, and L. Zarri: "Assessment of an Induction Motor Drive for High Speed Operation based on Matrix Converter", EPE2007 (2007)

( 4 ) K.-C. Kim: "A Novel Magnetic Flux Weakening Method of Permanent Magnet Synchronous Motor for Electric Vehicles", IEEE Trans., Vol.48, No.11, pp.4042-4045 (2012)

( 5 ) S.-M., Sue and C.-T. Pan: "Voltage-Constraint-Tracking-Based FieldWeakening Control of IPM Synchronous Motor Drives", IEEE Trans. Industrial Electronics, Vol.55, No.1, pp.340-347 (2008)

(6) S. Chaithongsuk, B. Nahid-Mobarakeh, N. Takorabet, and F. MeibodyTabar: "Optimal Design of Permanent Magnet Motors to Improve FieldWeakening Performances in Variable Speed Drives", IEEE Trans., Vol.59, No.6, pp.2484-2494 (2012)

( 7 ) Z. Fedyczak, P. Szczesniak, and I. Korotyeyev: "New Family of MatrixReactance Frequency Converters Based on Unipolar PWM AC MatrixReactance Choppers", EPE-PEMC 2008, P170, pp.236-24 (2008)

( 8 ) Z. Fedyczak, P. Szczesniak, and M. Klytta: "Matrix-Reactance Frequency Converter Based on Buck-Boost Topology", EPE-PEMC 2006, pp.763-768 (2006)

( 9 ) K. Koiwa and J. Itoh: "Experimental Verification of Effectiveness of Boostup Matrix Converter with V-connection AC Chopper", IEEJ Trans. IA, Vol.132, No.1, pp.1-8 (2012)

(10) J. Itoh, H. Tajima, and H. Ohsawa: "Induction Motor Drive System using Vconnection AC Chopper”, IEEJ Trans. IA, Vol.123, No.3, pp.271-277 (2003)

(11) T. Shinyama, M. Kawai, A. Torii, and A. Ueda: "Characteristic of an AC Chopper Circuit with LC Filters in the Input and Output Side", IEEJ Trans. IA, Vol.125, No.3, pp.205-211 (2005)

(12) J. Itoh, T. Iida, and A. Odaka: "Realization of High Efficiency AC link Converter System based on AC/AC Direct Conversion Techniques with RBIGBT", Industrial Electronics Conference, Paris, PF-012149 (2006)

(13) J. Itoh, I. Sato, H. Ohguchi, K. Sato, A. Odaka, and N. Eguchi: "A Control Method for the Matrix Converter Based on Virtual AC/DC/AC Conversion Using Carrier Comparison Method", IEEJ Trans. IA, Vol.124, No.5, pp.457463 (2004)

(14) I. Sato, J. Itoh, H. Ohguchi, A. Odaka, and H. Mine: "An Improvement Method of Matrix Converter Drives Under Input Voltage Disturbances", IPEC-Niigata, pp.546-551 (2005)

(15) K. Kato and J. Itoh: "Development of a Novel Commutation Method which Drastically Suppresses Commutation Failure of a Matrix Converter", IEEJ Trans. IA, Vol.127, No.8, pp.829-836 (2007)

Kazuhiro Koiwa (Student Member) received his B.S. and M.S. de-

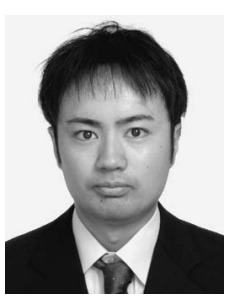
grees in electrical, electronics and information engineering from Nagaoka University of Technology, Nagaoka, Japan in 2010 and 2012, respectively. Since 2012, he has been with Nagaoka University of Technology as a Ph.D. degree student in electrical and electronics engineering. His research interests include AC-AC converters for renewable energy field and motor drive system. He is a student member of the Institute of Electrical Engineers of Japan.

Jun-ichi Itoh (Member) received his M.S. and Ph.D. degrees in elec-

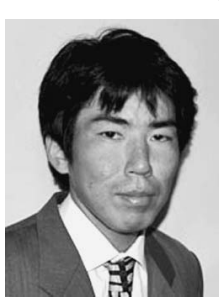
trical and electronic systems engineering from $\mathrm{Na}$ gaoka University of Technology, Nagaoka, Japan in 1996 and 2000, respectively. From 1996 to 2004, he was with Fuji Electric Corporate Research and Development Ltd., Tokyo, Japan. Since 2004, he has been with Nagaoka University of Technology as an associate professor. He received the IEEJ Academic Promotion Award (IEEJ Technical Development Award) in 2007. His research interests include matrix converters, DC/DC converters, power factor correction techniques and motor drives. He is a member of the Institute of Electrical Engineers of Japan. 